\title{
Efeito do laser de baixa potência na proliferação osteogênica de células-tronco mesenquimais do cordão umbilical humano
}

\author{
Effect of low power laser on osteogenic proliferation of human umbilical cord mesenchymal stem \\ cells
}

Efecto del láser de baja potencia en la proliferación osteogénica de las células madre mesenquimales del cordón umbilical humano

\author{
Bianca Maria Beserra Costa \\ ORCID: https://orcid.org/0000-0002-8132-9881 \\ Universidade de Pernambuco, Brasil \\ E-mail: bianca.bcosta@upe.br \\ Jorge Miguel Albrecht Ribeiro Filho \\ ORCID: https://orcid.org/0000-0002-3772-1851 \\ Faculdade de Odontologia do Recife, Brasil \\ E-mail: Jorge_albrechtfilho@ hotmail.com \\ Diogo Cabral de Melo Filho \\ ORCID: https://orcid.org/0000-0003-4239-109X \\ Universidade de Pernambuco, Brasil \\ E-mail: diogo.odonto1@gmail.com \\ Maria Alice dos Santos Silva \\ ORCID: https://orcid.org/0000-0002-8098-8869 \\ Universidade de Pernambuco, Brasil \\ E-mail: marialice10@hotmail.com \\ Maíra Letícia Ferreira de Santana \\ ORCID: https://orcid.org/0000-0002-2883-2912 \\ Universidade de Pernambuco, Brasil \\ E-mail: maira_leticia12@hotmail.com \\ Girlane Iris da Silva \\ ORCID: https://orcid.org/0000-0003-4178-3614 \\ Universidade de Pernambuco, Brasil \\ E-mail: girlaneiris14@gmail.com \\ Thamiris Micaeli Xavier dos Santos \\ ORCID: https://orcid.org/0000-0003-0211-6552 \\ Centro Universitário Maurício de Nassau, Brasil \\ E-mail: thamiris.mxs@gmail.com \\ José Raimundo dos Santos Neto \\ ORCID: https://orcid.org/0000-0003-4786-2639 \\ Centro Universitário Maurício de Nassau, Brasil \\ E-mail: jrs-neto@outlook.com \\ Antonio Ancelmo Neto \\ ORCID: https://orcid.org/0000-0002-1159-839X \\ Centro Universitário Maurício de Nassau, Brasil \\ E-mail: neto_antonioancelmo@hotmail.com \\ Ana Carolina Feliciano Gonçalves Lima \\ ORCID: https://orcid.org/0000-0001-7999-827X \\ Universidade de Pernambuco, Brasil \\ E-mail: anacarolina.fglima@hotmail.com
}

\begin{abstract}
Resumo
Este trabalho tem como objetivo avaliar o efeito do Laser de Baixa Potência no comprimento de onda vermelho de $660 \mathrm{~nm}$ na proliferação osteogênica das células-tronco mesenquimais do cordão umbilical humano. Foi realizado o processamento do cordão, que consiste na secção do cordão em fragmentos; lavagem com a solução; separação e descarte dos vasos do estroma; secção da geleia remanescente e colocação em garrafas de cultura com Meio DMEM suplementado com $15 \%$ de SFB, $20 \%$ de Ham F-12 Gibco ${ }^{\circledR}$ e antibióticos e mantidas em estufa de $\mathrm{CO} 2$ a $37^{\circ} \mathrm{C}$ e $5 \%$ de $\mathrm{CO} 2$; o meio de cultura foi trocado em $24 \mathrm{~h}$ e 7 dias, após esse período ficou sendo trocado a cada $72 \mathrm{~h}$, até a migração espontânea das células para a superfície; ao atingir a confluência de $80 \%$. As células foram utilizadas na terceira passagem, onde foram tripsinizadas, ressuspendidas e realizado a contagem do número de células para plaqueamento em 96 poços. 24 horas após o plaqueamento foram inseridos os indutores de diferenciação; e as células
\end{abstract}


pertencentes aos grupos de LBP foram irradiadas. A curva de proliferação foi realizada pelo ensaio de MTT. Foi adicionado solução contendo $0,5 \mathrm{mg}$ MTT por $\mathrm{mL}$ de meio, após incubação a $37^{\circ} \mathrm{C}$ por $4 \mathrm{~h}$ protegido da luz, o DMSO será adicionado às células. A absorbância foi lida através do espectrofotômetro a 562 nm com 24,48 e 72 horas para estabelecer curva de proliferação das células. A proliferação das CTMs foi maior nas células submetidas ao meio regular e o LBP apresentou efeito positivo na proliferação das CTMs associadas ao meio osteogênico.

Palavras-chave: Células-tronco; Cordão umbilical; Laser de baixa potência; Proliferação celular.

\begin{abstract}
This work aims to evaluate the effect of Low Power Laser at red wavelength of 660nm on osteogenic proliferation of human umbilical cord mesenchymal stem cells. Processing of the cord was performed, consisting of sectioning the cord into fragments; washing with the solution; separation and discarding of the stromal vessels; sectioning of the remaining jelly and placement in culture bottles with DMEM medium supplemented with 15\% SFB, 20\% Ham F-12 Gibco ${ }^{\circledR}$ and antibiotics and kept in a $\mathrm{CO} 2$ oven at $37^{\circ} \mathrm{C}$ and $5 \% \mathrm{CO} 2$; The culture medium was changed in $24 \mathrm{~h}$ and 7 days, after this period it was changed every $72 \mathrm{~h}$, until the spontaneous migration of cells to the surface; when $80 \%$ confluence was reached. The cells were used in the third passage, where they were trypsinized, resuspended, and the number of cells was counted for plating in 96 wells. 24 hours after plating, the differentiation inducers were inserted, and the cells belonging to the LBP groups were irradiated. The proliferation curve was performed by the MTT assay. Solution containing $0.5 \mathrm{mg}$ MTT per mL of medium was added, after incubation at $37^{\circ} \mathrm{C}$ for $4 \mathrm{~h}$ protected from light, DMSO will be added to the cells. The absorbance was read by spectrophotometer at $562 \mathrm{~nm}$ at 24,48 and $72 \mathrm{~h}$ to establish cell proliferation curve. The proliferation of MSCs was higher in cells submitted to the regular medium and LBP showed a positive effect on the proliferation of MSCs associated with the osteogenic medium.
\end{abstract}

Keywords: Stem cells; Umbilical cord; Low power laser; Cell proliferation.

\title{
Resumen
}

Este trabajo tiene como objetivo evaluar el efecto del láser de baja potencia en la longitud de onda roja de 660nm en la proliferación osteogénica de las células madre mesenquimales del cordón umbilical humano. Se realizó el procesamiento del cordón, que consistió en la sección del cordón en fragmentos; el lavado con la solución; la separación y el descarte de los vasos estromales; la sección de la gelatina restante y la colocación en frascos de cultivo con medio DMEM suplementado con 15\% de SFB, 20\% de Ham F-12 Gibco® y antibióticos y mantenido en una estufa de $\mathrm{CO} 2$ a $37^{\circ} \mathrm{C}$ y $5 \%$ de $\mathrm{CO} 2$; El medio de cultivo se cambió a las $24 \mathrm{~h}$ y a los 7 días, después de este periodo se cambió cada $72 \mathrm{~h}$ hasta la migración espontánea de las células a la superficie; cuando se alcanzó el $80 \%$ de confluencia. Las células se utilizaron en el tercer pasaje, en el que se tripsinizaron, se resuspendieron y se contó el número de células para su colocación en 96 pocillos. 24 horas después de la colocación, se introdujeron los inductores de diferenciación y se irradiaron las células pertenecientes a los grupos LBP. La curva de proliferación se realizó mediante el ensayo MTT. Se añadió una solución que contenía $0,5 \mathrm{mg}$ de MTT por $\mathrm{mL}$ de medio, tras incubar a $37{ }^{\circ} \mathrm{C}$ durante 4 h protegido de la luz, se añadirá DMSO a las células. La absorbancia se leyó en el espectrofotómetro a 562 $\mathrm{nm}$ a las 24, 48 y $72 \mathrm{~h}$ para establecer la curva de proliferación celular. La proliferación de las MSC fue mayor en las células sometidas al medio regular y el LBP mostró un efecto positivo en la proliferación de las MSC asociadas al medio osteogénico.

Palabras clave: Células madre; Cordón umbilical; Láser de baja potencia; Proliferación celular.

\section{Introdução}

As células-tronco mesenquimais (CTMs) são células indiferenciadas caracterizadas pela sua capacidade de autorrenovação, proliferação e diferenciação em diversos tipos de células e tecidos (multipotência). Essas células podem ser isoladas a partir de vários tecidos, como medula óssea, cordão umbilical, polpa dentária, ligamento periodontal e tecido adiposo (Casagrande et al., 2010; Kim et al., 2012; Soleimani et al., 2012; Ozeki et al., 2014; Barboza et al., 2014). Fatores químicos e físicos modulam a proliferação celular das CTMs. Os agentes químicos incluem fatores de crescimento e hormonais que participam desse processo (Barboza et al., 2014; Soltani et al., 2016).

Verificou-se que as CTMs secretam amplo espectro de citocinas e fatores de crescimento, fator de crescimento endotelial vascular (VEGF), particularmente a proteína-1 de monócitos, e fator de crescimento de hepatócitos. Esses fatores de crescimento estimulam a proliferação de fibroblastos, aceleram o processo de angiogênese e ajudam a resposta inflamatória e cicatrização das feridas. No entanto, é necessária a combinação de fatores de crescimento e agentes de diferenciação para provocar a diferenciação das células-tronco (Lipovsky et al., 2013; Ravindran et al., 2013). 
Diversos estudos têm demonstrado que fatores físicos como a irradiação de luz de baixa potência fornecida por diodos emissores de luz (LED) e Laser de baixa potência (LBP) promovem a aceleração da proliferação dessas células (Barboza et al., 2014; Soltani et al., 2016).

Os efeitos biomuladores do LBP a níveis celulares e moleculares têm sido demonstrados em vários estudos. O processo de fototerapia a Laser começa quando fótons são absorvidos por cromóforos biológicos, localizados em organelas (lisossomos e mitocôndrias) ou na membrana celular. Esses cromóforos interagem com os comprimentos de onda do Laser, convertendo a energia fotônica em energia química dentro da célula, sob a forma de Trifosfato de Adenosina (ATP), o que auxilia a normalização da função celular, o alívio da dor, modula a inflamação e acelera cicatrização, observando-se o aumento de proliferação e a sua diferenciação, assim como o aumento do conteúdo de cálcio citoplasmático (Koutná et al., 2003; Kim et al., 2012; Lipovsky et al., 2013; Soltani et al., 2016).

Diante desse contexto, a complexidade biológica e a arquitetura dos diversos tecidos, juntos à necessária vascularização, inervação e deposição de arcabouços de matriz extracelular caracterizam o grande desafio da Engenharia Tecidual. O órgão dentário, quando danificado por infecção bacteriana, lesão traumática ou desgaste, tem sua função restabelecida através da utilização de materiais sintéticos. A renovação desses tecidos dentários através das CTMs pode produzir novas perspectivas terapêuticas, sendo uma abordagem promissora para resolução dos problemas de perdas dentárias (Li et al., 2013; Ozeki et al., 2014).

Dessa forma, o potencial terapêutico das células-tronco e as perspectivas de uma medicina regenerativa são promissores. Assim, este trabalho tem como objetivo avaliar o efeito do Laser de Baixa Potência no comprimento de onda vermelho de $660 \mathrm{~nm}$ na proliferação osteogênica das células-tronco mesenquimais do cordão umbilical humano.

\section{Metodologia}

O projeto está cadastrado no Comitê de Ética, CAAE 36018214.2.0000.5207. Trata-se de um estudo laboratorial in vitro de amostras independentes, que simulará condições biológicas em laboratório, fornecendo bases e princípios que poderão ser estudados em ensaios clínicos. Foi utilizada a estrutura do Laboratório de Biofísica das membranas e células-tronco do Departamento de Biofísica e Radiobiologia da Universidade Federal de Pernambuco (UFPE), o equipamento de Laser do Centro de Biofotônica da Faculdade de Odontologia de Pernambuco - Universidade de Pernambuco (FOP- UPE) e a estrutura do Laboratório de Imunopatologia do Centro de Pesquisa Aggeu Magalhães.

\subsection{Obtenção do cordão umbilical}

Antes da coleta do cordão umbilical, os pais foram informados sobre os riscos e benefícios da pesquisa. Os progenitores que concordaram, assinaram o Termo de Consentimento Livre e Esclarecido (TCLE). O cordão umbilical (figura 1) foi coletado de forma padronizada no Hospital D’Ávila (convênio firmado com a UFPE) imediatamente após o parto cesariano e depositado em um recipiente de vidro com solução fisiológica estéril de tampão fosfato salino (PBS) e Ácido Etilenodiamino Tetra-acético (EDTA) (3mM), contendo Penicilina (200 UI/ml), Estreptomicina (200 g/ml) e Anfotericina B (5 $\mu \mathrm{g} / \mathrm{ml}$ ). O mesmo foi acondicionado e transportado em um cooler com gelo a uma temperatura aproximada de $4{ }^{\circ} \mathrm{C}$ para $\mathrm{o}$ Laboratório de Biofísica das membranas e células tronco do Departamento de Biofísica e Radiobiologia da UFPE. O intervalo entre a coleta e o processamento do cordão foi de no máximo 3 horas. 
Figura 1: Obtenção do cordão umbilical.

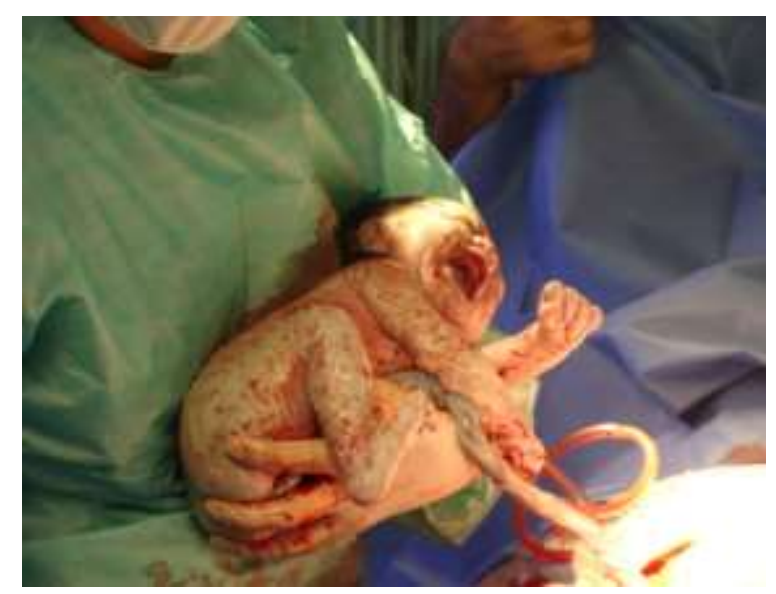

Fonte: Autores.

\subsection{Isolamento e cultura das células de cordão umbilical}

Dentro do fluxo laminar e com instrumental estéril, o cordão foi cortado em pedaços de aproximadamente $2 \mathrm{~cm}$ e lavado com a solução estéril fisiológica PBS/EDTA, até completa remoção do sangue e fluídos contidos nos vasos do cordão umbilical. Os vasos foram separados do estroma do cordão umbilical e em seguida descartados. A geleia tecidual remanescente foi cortada em pequenos pedaços quadrados com cerca de $0,5 \mathrm{~cm}$ de largura e colocados em garrafas de cultura com Meio Dulbecco de Eagle Modificado (DMEM) Gibco® suplementado com 15\% de Soro Fetal Bovino (SFB) Gibco®, 20\% de Ham F-12 Gibco® e antibióticos. As garrafas foram mantidas em estufa de $\mathrm{CO} 2$ a $37^{\circ} \mathrm{C}$ e $5 \%$ de $\mathrm{CO} 2$.

Figura 2: Processamento do cordão umbilical.

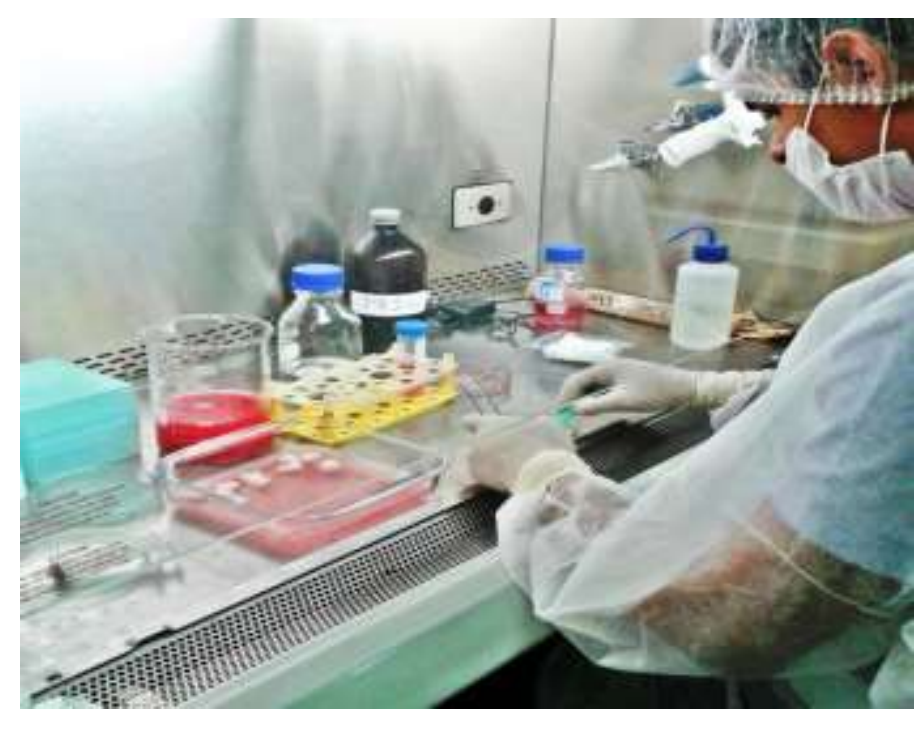

Fonte: Autores.

O meio de cultura foi trocado com 24 horas e os fragmentos foram mantidos em repouso por 7 dias. Decorrido este tempo, o meio de cultura foi trocado a cada 72 horas até que ocorra a migração espontânea das células da geleia de Wharton para a superfície plástica da garrafa de cultura e, com cerca de 21 dias, foi atingida uma confluência de aproximadamente $80 \%$. Atingida a confluência, os fragmentos de tecido foram removidos e as células foram tripsinizadas com uma solução $0,05 \%$ tripsina / 0,02\% EDTA/PBS durante 5 minutos, para que ocorra o seu desprendimento. Após o desprendimento das células, a solução de tripsina foi inativada com DMEM suplementado 15\% SFB. A alíquota obtida foi colocada em um falcon de $15 \mathrm{ml}$ e 
centrifugada (1200 rpm/ $5 \mathrm{~min}$ ) para obtenção do precipitado. O sobrenadante foi descartado e o precipitado foi distribuído em mais garrafas com DMEM suplementado $15 \% \mathrm{SFB}$, caracterizando a primeira passagem de células. O meio de cultura foi trocado a cada 72 horas, até que as células atinjam a confluência de $80 \%$ procedendo-se a segunda passagem. $\mathrm{O}$ experimento propriamente dito foi realizado após a terceira passagem das células, havendo em média uma semana de intervalo entre as passagens.

Figura 3: Plaqueamento do cordão umbilical.

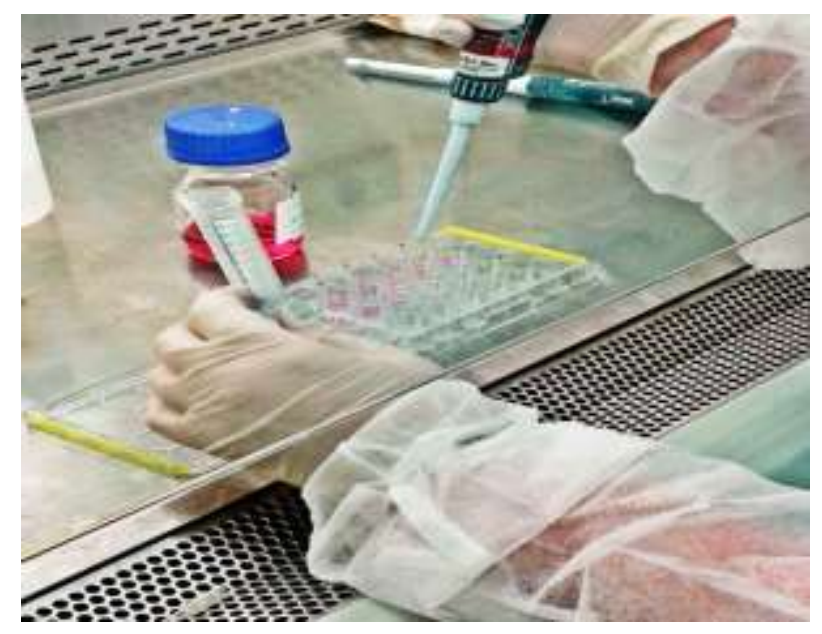

Fonte: Autores.

Realizada a terceira passagem e atingida a confluência de $80 \%$, as células foram analisadas para confirmar a sua natureza de células-troncos através da fenotipagem das células-tronco mesenquimais. As aquisições e analises foram realizadas no citômetro de fluxo FACScalibur (BD Bioscience, San Jose, CA, USA), disponível no Laboratório de Imunopatologia do Centro de Pesquisa Aggeu Magalhães, com um total de 30.000 eventos por amostra. As células foram incubadas com anticorpos monoclonais fluorescentes CD90 (eBioscience), CD44 e CD29 (Southern Biotech) associados a Isotiocianato de Fluorescceína (FITC), e CD45, CD34 e CD31 associados a Ficoeritrina (PE), todos diluídos 1/2000, mantidos a $4{ }^{\circ} \mathrm{C}$, por 60 $\min$.

Para os experimentos de diferenciação celular, as células foram tripsinizadas ressuspendidas e realizada a contagem do número de células para plaqueamento em 24 poços. Foi colocado em cada poço um volume correspondente a $5 \times 10^{4}$ células. As placas de cultura foram mantidas na estufa de $\mathrm{CO} 2$ a $37^{\circ} \mathrm{C}$ e $5 \%$ de $\mathrm{CO} 2$. A expansão das células foi monitorada diariamente (Oliveira et al., 2010).

\subsection{Meio indutor Osteogênico}

Após 24 horas de plaqueamento foram inseridos os indutores de diferenciação. O meio de diferenciação osteogênico

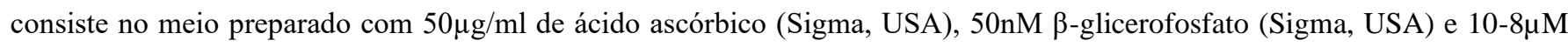
de dexametasona (Sigma, USA). As culturas de células com meio de indução ou controle tiveram seus meios trocados a cada 72 horas durante os 7 dias de experimento. A mesma quantidade de células foi mantida em meio DMEM suplementado com $15 \%$ de Soro Fetal Bovino (SFB) Gibco®, 20\% de Ham F-12 Gibco® e antibióticos caracterizando o controle de cultura. 


\subsection{Irradiação das células-tronco}

Após 24 horas de plaqueamento, as células pertencentes aos grupos de LBP foram irradiadas com Laser de Baixa Potência InGaAIP Thera Lase (DMC equipamentos, São Carlos, SP, BR), posicionando a ponteira do Laser perpendicularmente a tampa das placas de cultivo, no centro do poço, conforme os seguintes parâmetros: Comprimento de Onda Vermelho: 660nm, Potência: 30mW, Tempo de exposição: 28 segundos, Dose: $1 \mathrm{~J} / \mathrm{Cm} 2$.

Os grupos foram divididos da seguinte forma: G1: células crescidas em meio regular, G2: células crescidas em meio regular + LBP, G3: células crescidas em meio osteogênico, G4: células crescidas em meio osteogênico + LBP.

Figura 4: Placa com 24 poços para irradiação.

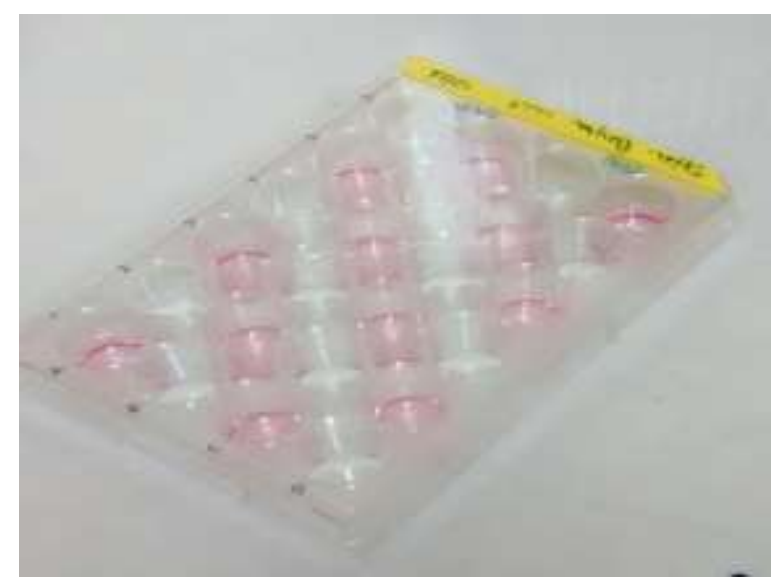

Fonte: Autores.

\subsection{Análise do efeito da irradiação a Laser na proliferação e viabilidade celular}

A viabilidade e proliferação celular após irradiação a Laser foi realizada pelo ensaio MTT que se baseia na medida do dano induzido pelo composto/extrato em estudo no metabolismo celular de glicídeos usualmente através da avaliação da atividade de desidrogenases mitocondriais. A viabilidade mitocondrial, e conseqüentemente, a viabilidade celular, é quantificada pela redução do MTT (um sal de coloração amarela e solúvel em água) a formazan (sal de coloração arroxeada e insolúvel em água) (Figura 5). Dessa forma, a redução do MTT a formazan, será diretamente proporcional à atividade mitocondrial e a viabilidade celular.

Figura 5: redução do MTT a formazan.
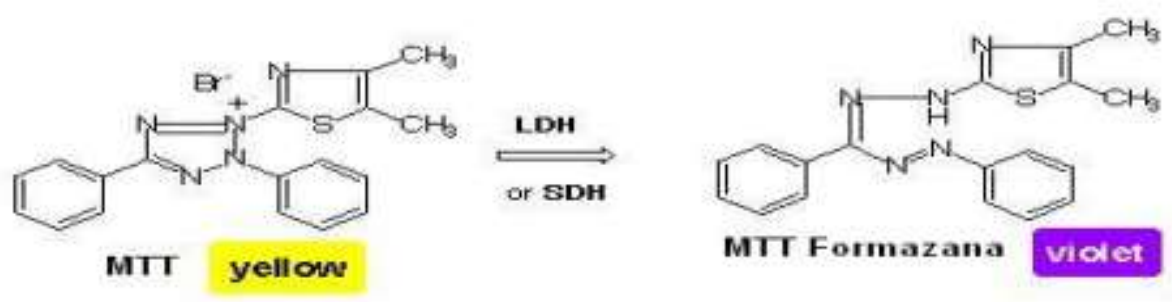

Fonte: Autores.

Para o ensaio MTT, as células foram cultivadas em placas de 24 poços a uma densidade de 5 x 104 células / poço na estufa de $\mathrm{CO} 2$ pelo período de 24 horas. Em seguida, foi retirado o meio de cultura e lavado com PBS. Adicionar solução contendo $0,5 \mathrm{mg}$ MTT por $\mathrm{mL}$ de meio. Após incubação a $37^{\circ} \mathrm{C}$ por $4 \mathrm{~h}$ protegido da luz, o DMSO foi adicionado às células. A absorvância foi lida através do espectrofotômetro a $562 \mathrm{~nm}$ com 24, 48, 72 e 96 horas para estabelecer curva de proliferação das células. Foram realizados pelo menos três experimentos independentes para verificar a reprodutibilidade dos resultados. 


\subsection{Análise estatística}

Os dados foram analisados descritivamente e através das medidas estatísticas: média, desvio padrão e coeficiente de variação, e inferencialmente através do teste de análise de multivariância (ANOVA) para grupos independentes e medidas repetidas. Os dados foram avaliados para conferir a igualdade de variância/discrepâncias e a distribuição normal de erros. A diferença entre os grupos foi avaliada pelo teste de Tukey com grau de significância de 5\%.

\section{Resultados e Discussão}

Os resultados mostram na Figura 6, a proliferação celular dos grupos medida nos dias 1, 3, 5 e 7, evidenciando a maior proliferação no grupo 1 (células crescidas em meio regular). A Tabela 1, indica as estatísticas do número de células por grupo e por dia. Desta tabela, se destaca que no primeiro dia, a média mais elevada foi no grupo 2 (células crescidas em meio regular + LBP); no terceiro dia, um menor número de células foi evidenciado no grupo 4 (células crescidas em meio osteogênico + LBP). No quinto dia, um número inferior de células foi verificado no grupo 3 (células crescidas em meio osteogênico), seguido do grupo 4, enquanto o grupo 1 apresentou a maior taxa de proliferação; no sétimo dia, o grupo 3 apresentou média inferior aos outros grupos. Com exceção do decréscimo da média do primeiro dia para o terceiro dia no grupo 4, as demais médias aumentaram com o dia de avaliação em todos os grupos para a margem de erro fixada (5\%) comprovando diferença significativa $(\mathrm{p}<0,05)$. Entre os dias em cada um dos grupos e através dos testes de comparações múltiplas verificou-se diferença significativa entre todos os dias no grupo 1; no grupo 2, exceto entre os dias 5 e 7 , apresentou diferenças significativas entre os pares de dias; no grupo 3, se comprova diferença significativa entre o dia 1 dos dias 5 e 7; no grupo 4, foram verificadas diferenças significativas dos dois dias iniciais dos dias finais ( 1 e 3 dos dias 5 e 7). Com exceção do primeiro dia, se comprova diferença significativa entre os grupos, sendo com diferenças significativas: no terceiro dia, entre o grupo 1 com cada um dos grupos 3 e 4; do grupo 2 com o grupo 4; nos dias 5 e 7, as diferenças ocorreram entre os grupos com 1 e 2 dos grupos 3 e 4.

A variabilidade expressa através do coeficiente de variação não foi elevada desde que a referida medida foi no máximo 47,38\% (<50\%) no dia 1 do grupo 3.

Figura 6: Curvas de crescimento das células-tronco mesenquimais submetidas ou não ao meio osteogênico; submetidas ou não à irradiação pelo LBP; submetidas à associação do meio osteogênico e irradiação com LBP.

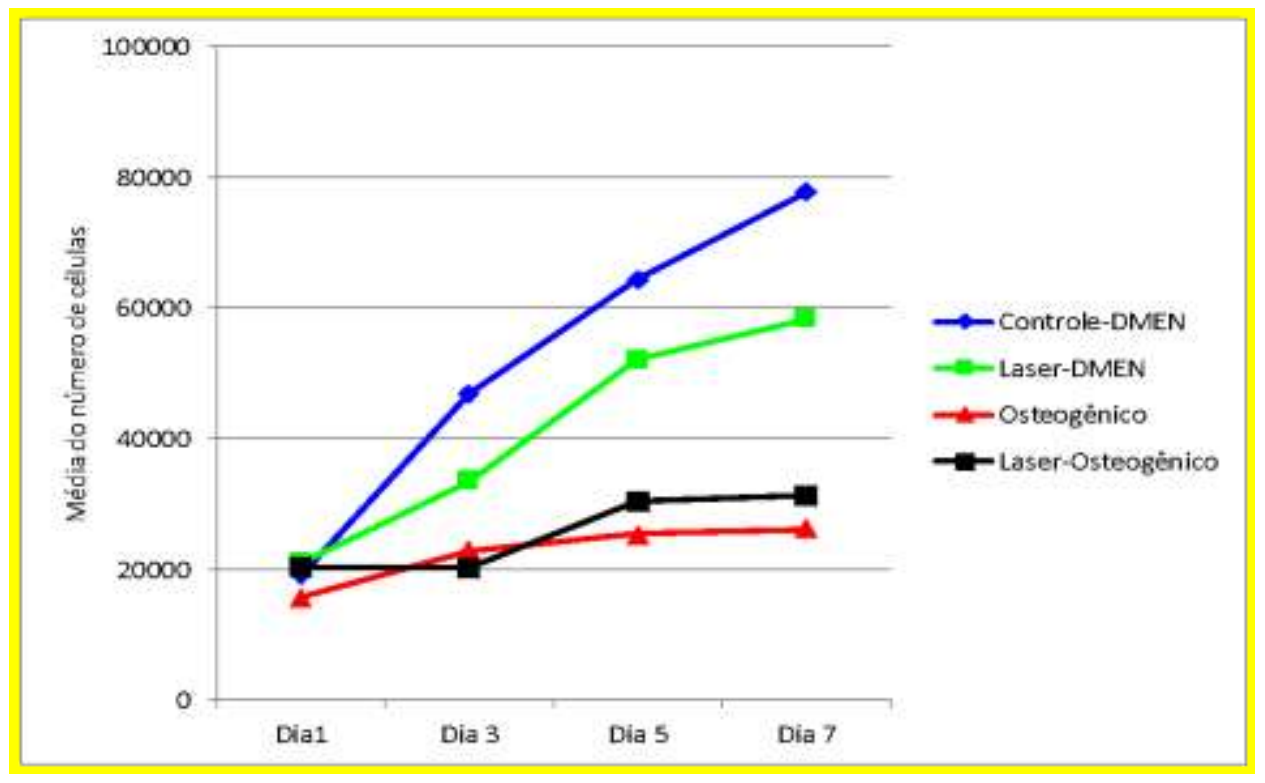

Fonte: Autores. 
Research, Society and Development, v. 11, n. 2, e37011224921, 2022

(CC BY 4.0) | ISSN 2525-3409 | DOI: http://dx.doi.org/10.33448/rsd-v11i2.24921

Tabela 1: Estatísticas do número de células segundo o grupo e o dia de avaliação.

\begin{tabular}{|c|c|c|c|c|c|c|}
\hline \multirow{3}{*}{$\begin{array}{l}\text { Grupo } \\
\text { Grupo } 1\end{array}$} & \multicolumn{6}{|c|}{ Dia de avaliação } \\
\hline & Estatística & Dia1 & Dia 3 & Dia 5 & Dia 7 & Valor p \\
\hline & Média & $19183,33^{(a)}$ & $46911,11^{(\mathrm{b}, \mathrm{A})}$ & $64350,00^{(\mathrm{c.A})}$ & $77733,33^{(\mathrm{d}, A)}$ & $\mathrm{p}^{(1)<0} 0,001^{*}$ \\
\hline & Desvio padrão & 5345,53 & 12626,21 & 11166,13 & 13739,72 & \\
\hline & Mediana & 17500,00 & 50200,00 & 64750,00 & 75200,00 & \\
\hline & Coef. Variação & 27,87 & 26,92 & 17,35 & 17,68 & \\
\hline \multirow[t]{4}{*}{ Grupo 2} & Média & $21111,11^{(a)}$ & $33566,67^{(\mathrm{D}, \mathrm{AB})}$ & $52133,33^{(\mathrm{c}, \mathrm{A})}$ & $58355,56^{(\mathrm{c}, A)}$ & $\mathrm{p}^{(1)<0}, 001^{*}$ \\
\hline & Desvio padrão & 6432,04 & 8077,44 & 8872,43 & 7403,23 & \\
\hline & Mediana & 20800,00 & 28400,00 & 53000,00 & 56000,00 & \\
\hline & Coef. Variação & 30,47 & 24,06 & 17,02 & 12,69 & \\
\hline \multirow[t]{4}{*}{ Grupo 3} & Média & $15711,11^{(a)}$ & $22977,78^{\text {(ab, Bc) }}$ & $25444,44^{(\mathrm{b}, \mathrm{B})}$ & $26311,11^{(\mathrm{b}, \mathrm{B})}$ & $\mathrm{p}^{(1)}=0,040^{*}$ \\
\hline & Desvio padrão & 7443,19 & 8918,21 & 5808,42 & 10000,56 & \\
\hline & Mediana & 15800,00 & 24000,00 & 25200,00 & 22200,00 & \\
\hline & Coef. Variação & 47,38 & 38,81 & 22,83 & 38,01 & \\
\hline \multirow[t]{4}{*}{ Grupo 4} & Média & $20311,11^{(a)}$ & $20177,78^{(\mathrm{a}, \mathrm{C})}$ & $30400,00^{(\mathrm{b}, \mathrm{B})}$ & $31311,11^{(\mathrm{b}, \mathrm{B})}$ & $\mathrm{p}^{(1)<0}, 001^{*}$ \\
\hline & Desvio padrão & 5009,10 & 7460,19 & 4224,93 & 4983,08 & \\
\hline & Mediana & 20000,00 & 19600,00 & 30200,00 & 31600,00 & \\
\hline & Coef. Variação & 24,66 & 36,97 & 13,90 & 15,91 & \\
\hline Valor p & & $p^{(2)}=\mathbf{0 , 1 7 8}$ & $\mathbf{p}^{(2)}<0,001 *$ & $\mathbf{p}^{22}<0,001 *$ & $\mathbf{p}^{(2)<0,001} *$ & \\
\hline
\end{tabular}

Fonte: Autores.

A variabilidade expressa através do coeficiente de variação não foi elevada visto que a referida medida foi no máximo $47,38 \%(<50 \%)$ no dia 1 do grupo 3. Para a margem de erro fixada (5\%) se comprova diferença significativa $(\mathrm{p}<0,05)$ entre os dias em cada um dos grupos.

A Tabela 2 apresenta as diferenças das médias de cada um dos dias das médias do dia 1 por grupo. Esta tabela mostra que o único valor negativo ocorreu na diferença do dia 3 - dia 1 no grupo 4; os maiores aumentos ocorreram no grupo 1, seguido do grupo 2. 
Tabela 2: Diferenças entre as médias da variação dos dias 3, 5 e 7 para o dia 1 segundo o grupo.

\section{Diferença}

\section{Grupo Dia 3-Dia 1 Dia 5-Dia 1 Dia 7-Dia 1}

\begin{tabular}{llll} 
Grupo 1 & 27727,78 & 45166,67 & 58550,00 \\
Grupo 2 & 12455,56 & 31022,22 & 37244,45 \\
Grupo 3 & 7266,67 & 9733,33 & 10600,00 \\
& & & \\
Grupo 4 & $-133,33$ & 10088,89 & 11000,00 \\
\hline
\end{tabular}

Fonte: Autores.

Esta tabela mostra que o único valor negativo ocorreu na diferença do dia 3 - dia 1 no grupo 4 o que indica redução; os maiores aumentos ocorreram no grupo 1 , seguido do grupo 2 .

\section{Conclusão}

A proliferação das células-tronco mensequimais foi maior nas células submetidas ao meio regular e o Laser de baixa potência (LBP) apresentou efeito positivo na proliferação das CTMs associadas ao meio osteogênico.

\section{Referências}

Abramovitch-Gottlib, L., Gross, T., Naveh, D., Geresh, S., Rosenwaks, S., Bar, I., \& Vago, R. (2005). A irradiação com laser de baixa intensidade estimula o fenótipo osteogênico de células-tronco mesenquimais semeadas em uma biomatriz tridimensional. Lasers in Medical Science, 20 (3), $138-146$.

AlGhamdi, KM, Kumar, A., \& Moussa, NA (2012). Terapia a laser de baixa potência: uma técnica útil para aumentar a proliferação de várias células em cultura. Lasers in medical science, 27 (1), 237-249.

Anzalone, R., Iacono, ML, Loria, T., Di Stefano, A., Giannuzzi, P., Farina, F., \& La Rocca, G. (2011). Células-tronco mesenquimais de geléia da Wharton como candidatas à regeneração de células beta: estendendo os benefícios diferenciadores e imunomoduladores das células-tronco mesenquimais adultas para o tratamento do diabetes tipo 1. Stem Cell Reviews and Reports, 7 (2), 342-363.

Asgary, S., Nazarian, H., Khojasteh, A., \& Shokouhinejad, N. (2014). Expressão gênica e liberação de citocinas durante a diferenciação odontogênica de células-tronco da polpa dentária humana induzida por 2 biomateriais endodônticos. Journal of endodontics, 40 (3), $387-392$.

Augello, A., Kurth, T. B., \& De Bari, C. (2010). Células-tronco mesenquimais: uma perspectiva das culturas in vitro à migração in vivo e nichos. Eur Cell Mater, 20 (121), e 33.

Barboza, C. A. G., Ginani, F., Soares, D. M., Henriques, Á. C. G., \& Freitas, R. D. A. (2014). Laser de baixa intensidade induzida à proliferação in vitro de células-tronco mesenquimais. Einstein (São Paulo), 12, 75-81.

Can, A., \& Karahuseyinoglu, S. (2007). Revisão concisa: estroma de cordão umbilical humano em relação à origem das células-tronco derivadas do feto. Células-tronco, 25 (11), 2886-2895.

Caplan, AI (2005). Células-tronco mesenquimais: terapia reconstrutiva baseada em células em ortopedia. Tissue engineering, 11 (7-8), $1198-1211$.

Casagrande, L., Lauxen, I. S., \& Fernandes, M. I. (2009). O emprego da engenharia tecidual na odontologia. Revista da Faculdade de Odontologia de Porto Alegre, 50(1), 20-23.

Cepera, F., Angelieri, F., Bommarito, S., \& Siqueira, D. F. (2008). Efeito do laser de baixa intensidade na expansão rápida da maxila. Ortodontia, $222-226$.

Chen, Y., Yu, Y., Chen, L., Ye, L., Cui, J., Sun, Q., \& Liu, L. (2015). Células-tronco mesenquimais de cordão umbilical humano: uma nova opção terapêutica para regeneração dentária. Stem Cells International.

Fong, C. Y., Chak, L. L., Biswas, A., Tan, J. H., Gauthaman, K., Chan, W. K., \& Bongso, A. (2011). As células-tronco gelatinosas humanas de Wharton têm perfis de transcriptoma exclusivos em comparação com as células-tronco embrionárias humanas e outras células-tronco mesenquimais. Revisões e relatórios de células-tronco, 7 (1), 1-16. 
Gao, Y., Zhao, G., Li, D., Chen, X., Pang, J., \& Ke, J. (2014). Avaliação do potencial de isolamento e diferenciação múltipla de células-tronco mesenquimais gengivais humanas. Jornal internacional de ciências moleculares, 15 (11), 20982-20996.

Genovese, W. J. (2007). Laser of Low Intensity. Therapeutic Applications in Dentistry. Santos.

Giannelli, M., Chellini, F., Sassoli, C., Francini, F., Pini, A., Squecco, R., \& Formigli, L. (2013). Fotoativação de células estromais mesenquimais da medula óssea com laser de diodo: efeitos e mecanismos de ação. Journal of Cellular Physiology, 228 (1), 172-181.

Ginani, F., Soares, D. M., \& Barboza, C. A. G. (2015). Efeito da terapia a laser de baixa potência na proliferação de células-tronco mesenquimais: uma revisão sistemática. Lasers in medical science, 30 (8), 2189-2194.

Lucke, L. D. (2018). Efeito combinado da aplicação de células tronco e laser de baixa potência sobre a cicatrização do tendão calcanear de ratos após transecção parcial.

Guo, W., Gong, K., Shi, H., Zhu, G., He, Y., Ding, B., ... \& Jin, Y. (2012). Células do folículo dentário e arcabouço da matriz dentinária tratada para a engenharia de tecidos da raiz do dente. Biomaterials, 33 (5), 1291-1302.

Gutknecht, N., \& Franzen, R. O. (2004). Laser: função, interação e segurança. Gutknecht N, Eduardo CP A Odontologia e o Laser, Quintessence Editora Ltda, 25-39.

Horvát-Karajz, K., Balogh, Z., Kovács, V., Drrernat, AH, Sreter, L., \& Uher, F. (2009). Efeito in vitro da carboplatina, citarabina, paclitaxel, vincristina e irradiação a laser de baixa potência em células-tronco mesenquimais murinas. Lasers em cirurgia e medicina: The Official Journal ofthe American Society for Laser Medicine and Surgery, 41 (6), 463-469.

Iwashima, S., Ozaki, T., Maruyama, S., Saka, Y., Kobori, M., Omae, K., \& Matsuo, S. (2009). Novo sistema de cultura de células estromais mesenquimais de tecido adiposo subcutâneo humano. Células-tronco e desenvolvimento, 18 (4), 533-544.

Kern, S., Eichler, H., Stoeve, J., Klüter, H., \& Bieback, K. (2006). Análise comparativa de células-tronco mesenquimais da medula óssea, sangue do cordão umbilical ou tecido adiposo. Células-tronco, 24 (5), 1294-1301.

Kim, H., Choi, K., Kweon, O K, \& Kim, W. H (2012). Efeito de cicatrização de feridas aprimorado de células-tronco mesenquimais derivadas de tecido adiposo canino com terapia a laser de baixa intensidade em camundongos atímicos. Journal of dermatological science, 68 (3), 149-156.

Kidwai, F. K, Movahednia, M. .M, Iqbal, K., Jokhun, D S, Cao, T., \& Fawzy, A. S (2014). Diferenciação de células-tronco embrionárias humanas em linhagem odontoblástica: um estudo in vitro. International Endodontic Journal, 47 (4), 346-355.

Kolya, C. L., \& Castanho, F. L. (2007). Células-tronco e a odontologia. ConScientiae Saúde, 6(1), 165-171.

Ferrari, J. C. L. (2005). Efeito do laser terapêutico na mucosite induzida por 5-fluoruracila (5-FU) em hamsters.

Kushibiki, T., Hirasawa, T., Okawa, S., \& Ishihara, M. (2013). A irradiação com laser azul gera espécies reativas de oxigênio intracelular em vários tipos de células. Fotomedicina e cirurgia a laser, 31 (3), 95-104.

Leonida, A., Paiusco, A., Rossi, G., Carini, F., Baldoni, M., \& Caccianiga, G. (2013). Efeitos da irradiação com laser de baixa intensidade na proliferação e diferenciação osteoblástica de células-tronco mesenquimais humanas semeadas em uma biomatriz tridimensional: estudo piloto in vitro. Lasers in medical science, $28(1), 125-132$.

Li, TX, Yuan, J., Chen, Y., Pan, LJ, Song, C., Bi, LJ, \& Jiao, XH (2013). Diferenciação de células-tronco mesenquimais de tecido de cordão umbilical humano em células semelhantes a odontoblastos usando o meio condicionado de células germinativas de dente in vitro. BioMed research international.

Lipovsky, A., Oron, U., Gedanken, A., \& Lubart, R. (2013). A irradiação com luz visível de baixo nível (LLVL) promove a proliferação de células-tronco mesenquimais. Lasers in medical science, 28 (4), 1113-1117.

Mafi, R., Hindocha, S., Mafi, P., Griffin, M., \& Khan, WS (2011). Suplemento 2: Fontes de células-tronco mesenquimais adultas aplicáveis para aplicações musculoesqueléticas - uma revisão sistemática da literatura. The open ortopedia journal, 5, 242.

Mvula, B., Mathope, T., Moore, T., \& Abrahamse, H. (2008). O efeito da irradiação de laser de baixo nível em células-tronco derivadas de adiposo humano adulto. Lasers in medical science, 23 (3), 277-282.

Mvula, B., Moore, T. J \& Abrahamse, H. (2010). Efeito da irradiação de laser de baixa intensidade e fator de crescimento epidérmico em células-tronco humanas adultas derivadas de gordura. Lasers in Medical Science, 25 (1), 33-39.

Oliveira, C. F, Hebling, J., Souza, P. P. C. D., Sacono, N. T, Lessa, F. R, Lizarelli, R. F. Z., \& Costa, C. A. D. S. (2008). Efeito da irradiação de laser de baixa intensidade em células semelhantes a odontoblastos. Laser Physics Letters, 5 (9), 680.

Lizandra de Miranda Oliveira, A. (2010). Isolamento, expansão e diferenciação osteogênica de células-tronco mesenquimais obtidas de cordão umbilical humano (Master's thesis, Universidade Federal de Pernambuco).

Overman, J. R., Helder, M. N., Ten Bruggenkate, C. M., Schulten, E. A., Klein-Nulend, J., \& Bakker, A. D. (2013). Perfis de expressão gênica de fator de crescimento de células-tronco adiposas humanas tratadas com proteína morfogenética óssea 2 semeadas em estruturas de fosfato de cálcio in vitro. Biochimie, 95 (12), 2304-2313.

Ozeki, N., Mogi, M., Yamaguchi, H., Hiyama, T., Kawai, R., Hase, N., \& Kramer, RH (2014). A diferenciação de células-tronco do músculo esquelético humano em odontoblastos depende da indução da expressão da integrina $\alpha 1$. Journal of Biological Chemistry, 289 (20), 14380-14391.

Park, I. S, Chung, P. S, \& Ahn, J. C (2015). O agrupamento de células do estroma derivado do adiposo com terapia de luz aumenta a angiogênese e a cicatrização de feridas cutâneas em camundongos. Comunicações de pesquisa bioquímica e biofísica, 462 (3), 171-177. 
Research, Society and Development, v. 11, n. 2, e37011224921, 2022

(CC BY 4.0) | ISSN 2525-3409 | DOI: http://dx.doi.org/10.33448/rsd-v11i2.24921

Pereira, L. B, Chimello, D. T, Wimmers Ferreira, M. R, Bachmann, L., Rosa, A. L, \& Bombonato-Prado, K. F (2012). A terapia a laser de baixo nível influencia a resposta celular semelhante ao odontoblast de camundongo in vitro. Fotomedicina e cirurgia a laser, 30 (4), 206-213.

Pereira, L. O, Longo, J. P. F, \& Azevedo, R. B (2012). A irradiação com laser não aumentou a proliferação ou a diferenciação das células-tronco da polpa dentária normal e inflamada. Arquivos de biologia oral, 57 (8), 1079-1085.

Ravindran, S., Zhang, Y., Huang, C. C, \& George, A. (2014). Indução odontogênica de células-tronco dentárias por andaime tridimensional inspirado na matriz extracelular. Tissue Engineering Part A, 20 (1-2), 92-102.

Ravindran, S., Zhang, Y., Huang, C. C, \& George, A. (2014). Indução odontogênica de células-tronco dentárias por andaime tridimensional inspirado na matriz extracelular. Tissue Engineering Part A, 20 (1-2), 92-102.

Ravindran, S., \& George, A. (2015). Diferenciação de células-tronco somáticas mediada por matriz extracelular biomimética: aplicações na regeneração de tecido pulpar. Fronteiras em fisiologia, 6, 118 .

Ren, H., Sang, Y., Zhang, F., Liu, Z., Qi, N., \& Chen, Y. (2016). Análise comparativa de células-tronco mesenquimais humanas do cordão umbilical, polpa dentária e sangue menstrual como fontes para terapia celular. Células-tronco internacionais, 2016.

Santos, C. P. D. (2014). Estudo da interação entre células-tronco transplantadas e células do hospedeiro na bioengenharia pulpar (Doctoral dissertation, Universidade de São Paulo).

Seo, B. M, Miura, M., Gronthos, S., Bartold, P. .M, Batouli, S., Brahim, J., \& Shi, S. (2004). Investigação de células-tronco pós-natais multipotentes do ligamento periodontal humano. The Lancet, 364 (9429), 149-155.

Silva, L. B, Neto, A. P. D. S., Pacheco, R. G. P., Júnior, S. A., de Menezes, R. F., Carneiro, V. S. M., \& Sobral, A. P. V. (2016). As aplicações promissoras das células-tronco na região oral: revisão da literatura. The open dentistry journal, 10, 227.

Soares, A. P., Knop, L. A. H., Jesus, A. A. D., \& Araújo, T. M. D. (2007). Células-tronco em odontologia. Revista Dental Press de Ortodontia e Ortopedia Facial, 12, 33-40.

Soares, D. M., Ginani, F., Henriques, Á. G., \& Barboza, C. A. G (2015). Efeitos da terapia a laser na proliferação de células-tronco do ligamento periodontal humano. Lasers in medical science, 30 (3), 1171-1174.

Antunes, F. G. (2017). Efeito do laser de baixa intensidade na atividade biológica de células-tronco da polpa de dentes decíduos humanos.

Soltani, S. D, Babaee, A., Shojaei, M., Salehinejad, P., Seyedi, F., JalalKamali, M., \& Nematollahi-Mahani, S. N. (2016). Diferentes efeitos da irradiação de luz vermelha e verde dependente de energia na proliferação de células mesenquimais derivadas da matriz do cordão umbilical humano. Lasers in medical science, 31 (2), 255-261.

Stein, A., Benayahu, D., Maltz, L., \& Oron, U. (2005). A irradiação com laser de baixa intensidade promove a proliferação e diferenciação de osteoblastos humanos in vitro. Photomedicine and Laser Therapy, 23 (2), 161-166.

Taşlı, P. N, Aydın, S., Yalvaç, M. E, \& Şahin, F. (2014). Bmp 2 e bmp 7 induzem odonto e osteogênese de células-tronco germinativas de dente humano. Applied biohemistry and biotechnology, 172 (6), 3016-3025. 